\title{
Editorial
}

\section{Mechatronics as challenge for higher competitiveness}

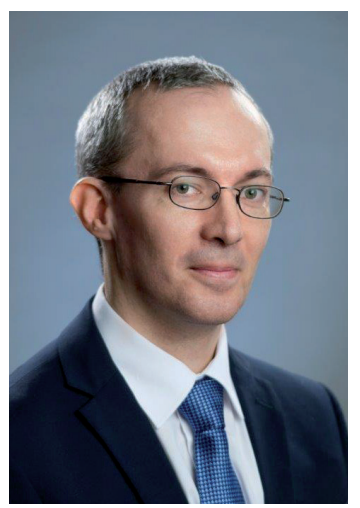

\section{prof. Ing. Michal Kelemen, PhD.}

Technical University of Košice, Faculty of Mechanical Engineering, Institute of Automation, Mechatronics and Robotics, Department of Mechatronics

Michal Kelemen, prof. Ing. PhD. (born in 1974) is a professor of the Department of Mechatronics at the Faculty of Mechanical Engineering at the Technical University of Košice, Slovakia. He received M.S. degree in mechanical engineering from Technical University of Košice, Slovakia in 1998 and Ph.D. degree in Mechatronics from Technical University of Košice, Slovakia in 2002. He has been awarded in the 1998 "Price of the VolksBank" for the best M.S. graduate and 2007 Price "Scientist of the year". His research interests include mechatronic systems, intelligent robotic systems, measurement of non-electric quantities, and microcomputer systems. He has authored more than 200 journal and conference papers on these topics.

Mechatronics is synergy combination of mechanics, electronics and intelligent control with aim to develop improved products with higher competitiveness.

Mechatronics is not limited only to mechanics, electronics and computer control, but it is synergy integration of precision engineering, intelligent computer control, software engineering, hydraulics, pneumatics etc. It means that mechatronics has multidisciplinary character.

Mechatronic products substitutes the standard mechanical products or their part. It is as result of rapid developing of microelectronics and growing global competition on the market. Developing time has to be as shorter as possible and also there is a great need for effectivity of product development. Very long time-consuming developing process of products causes the low profit from these products.

Mechatronic designer is under enormous press caused from wide spectrum of problems related to design of mechatronic products with improved properties and higher quality as soon as possible. There are also next properties expected from mechatronics products as:

$\checkmark$ user friendly behaviour,

$\checkmark$ flexible operation,

$\checkmark$ low energy consumption,

$\checkmark$ small size and low weight,

$\checkmark$ low price etc.

Design process has the most important key role in product development. This approach is philosophy of the successful corporations and business companies.

In the mechatronic product design process, there is a risk that mechanics of product will be designed on the level, where no electronics and informatics will enables target functionality of product. System thinking approach in design process enables parallel developing of particular subsystems of mechatronic product already in early stage of design. This approach 


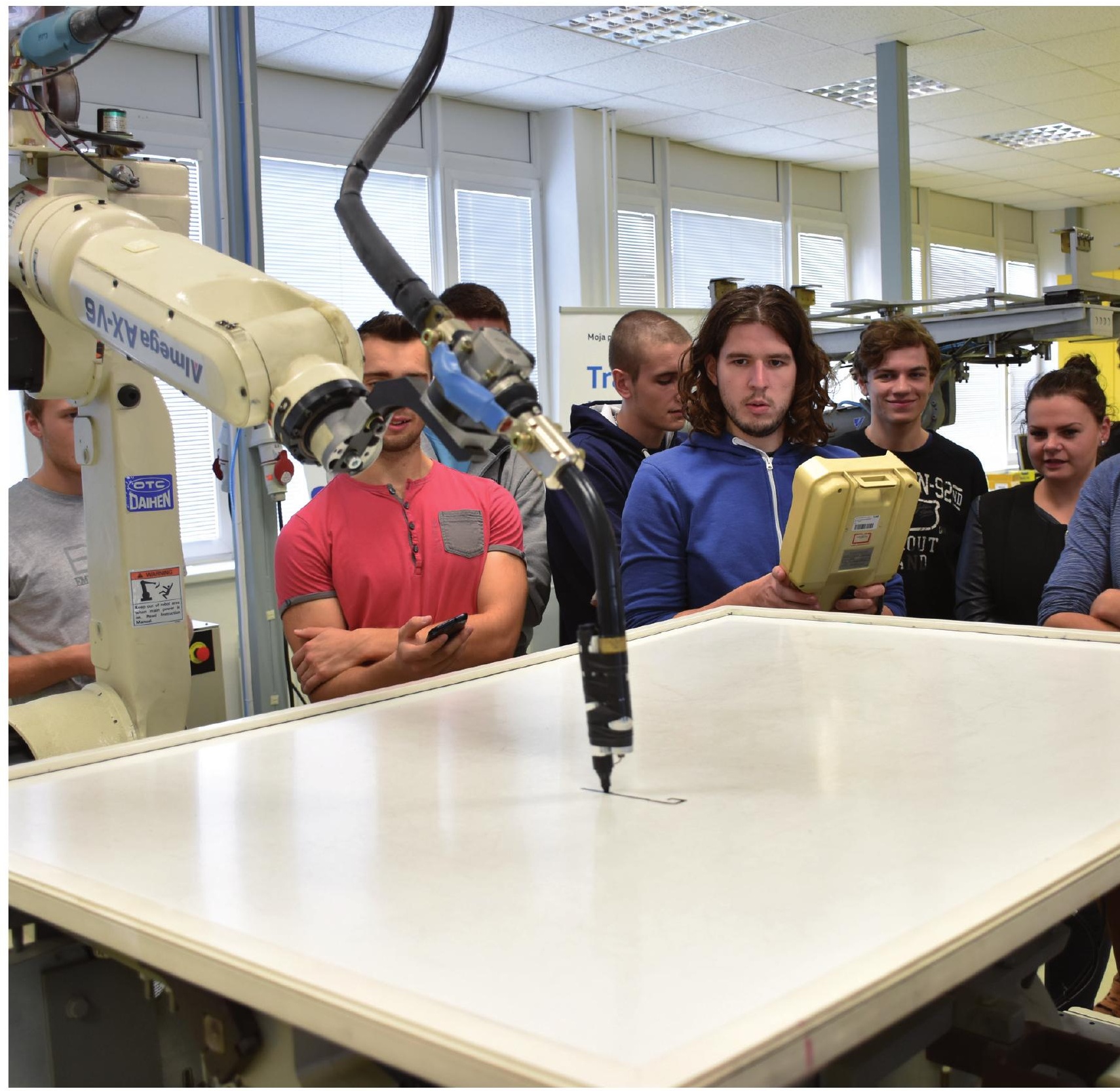

enables to uncover problems very early and it helps to prevents before wrong design of mechatronic product. Mechatronic approach is parallel concurrent engineering raised with synergy effect of achieved in design process of product.

Key tool for the mechatronic design is modelling and simulation. It is also called as model based design. Analysis and simulation of subsystems realized in early stage design helps in finding of optimal design solution. Significant contribution of model based design is acceleration of design process and also cost saving in design process and prototype creation.

Diversity, heterogeneity and continual development of mechatronic products caused that, it is very complicated to determine uniform and universal methodology for design of mechatronic products. However, there are unified methodologies defined through the standard VDI 2422 a VDI 2206. 